\title{
A afromoda e 0 estilista Isaac Silva
}

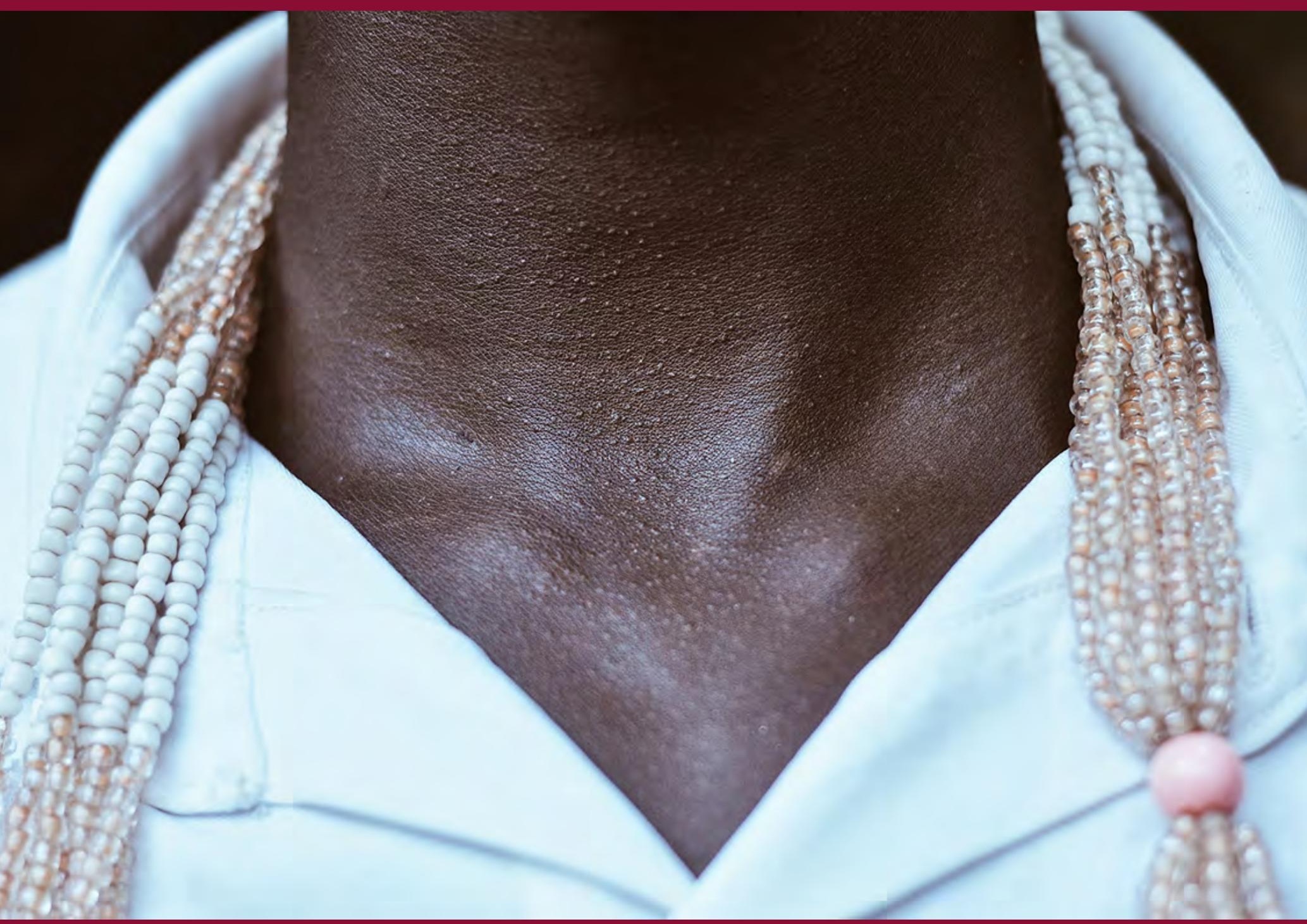




\section{Entrevistadora: Sheila Cristina Silva Aragão Caetano ${ }^{1}$} ORCID: https://orcid.org/0000-0001-6000-4378

\section{Entrevista realizada em São Paulo, 24 de março de 2020.}

\section{A afromoda e o estilista Isaac Silva}

Estamos acostumados a viver em uma sociedade que privilegia o conhecimento do vencedor, de quem está no poder. Assim a história acaba por escrever uma narrativa única, inclusive a da moda. Contudo, a partir da École des Annales, a história abre espaço para que sejam contadas outras histórias além das dominantes: começa a ser valorizada a história oral.

Quando pensamos na sociedade brasileira, a cultura e a história afro-brasileiras ainda são pouco divulgadas, sendo preciso pesquisar e escrever mais a respeito, vencendo assim as barreiras dos preconceitos que por aqui estão enraizados. Como esta edição da revista dObras[s] está dedicada a abordar a Afromoda: o uso das roupas e das aparências em corpos políticos, é válido escrever na história da moda uma narrativa mais plural, que valorize a cultura e a história afro-brasileiras.

O lugar de pessoas negras é em todo lugar, inclusive no mundo da moda, porém o racismo que estrutura a sociedade brasileira dificulta e minimiza tanto a sua entrada no mercado de trabalho como estilistas quanto a divulgação da cultura afro-brasileira sem a apropriação cultural.

FIGURA 1 - DESFILE LAB FANTASMA 42, SPFW

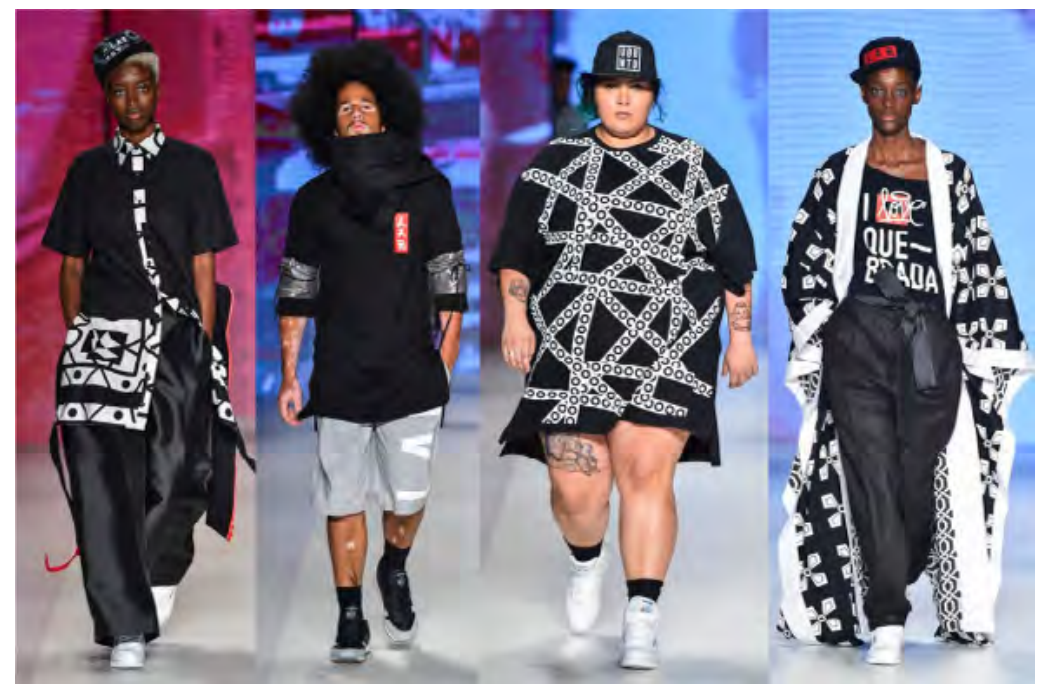

FONTE: Glambox². Disponível em: https://www.glambox.com.br/mag/ler/3928/lab-arrasa-com-desfiledemocratico-na-spfw-trans-n42/. Acesso em: 6 set. 2020.

\footnotetext{
1 Mestre em Educação, Arte e História da Cultura pela Universidade Presbiteriana Mackenzie. Professora Adjunta I da Faculdade Zumbi dos Palmares. E-mail: sheila.aragao@icloud.com. Lattes: http:// lattes.cnpq.br/7598786817782412.

2 LAB ARRASA COM DESFILE DEMOCRÁTICO NA SPFW TRANS N42. Disponível em: https://www.glambox.com. br/mag/ler/3928/Lab-arrasa-com-desfile-democratico-na-spfw-trans-n42/. Acesso em: 6 set. 2020.
} 
Na 38 edição da São Paulo Fashion Week (SPFW), foi o début da grife Apartamento 03, já consolidada no mercado, do mineiro Luiz Claudio Silva. Contudo, quando a marca LAB Fantasma estreou na $42^{\mathrm{a}}$ edição do evento, com a coleção Yasuke (figura 1), inovou não só por exibir diferentes tipos de corpos, sendo a maioria negros, mas também por levar a cultura afro-brasileira à passarela por olhos negros. Na $48^{a}$ edição da SPFW, estavam à frente da direção criativa e do styling da Cavalera Léo Bronks e Emerson Timba, ambos sendo lançados como diretores criativos da coleção intitulada Skate, punk e Jamaica no país do futebol (figura 2). Léo Bronks e Emerson Timba atuam há alguns anos no mercado da moda como stylists, em videoclipes, e consultores de estilo para personalidades, e eles fazem do desfile da Cavalera, além de moda, um ato político, tanto no início, quando mostram um vídeo do cantor Seu Jorge falando sobre o grande número de pessoas negras que são mortas diariamente, quanto no fim da apresentação, quando exibem os cartazes com as frases "Foda-se o racismo Cavalera" e "Foda-se o fascismo Cavalera". Afora exibirem modelos trans desfilando com diversos tipos de outros corpos.

\section{FIGURA 2 - COMPOSIÇÃO DO DESFILE DA CAVALERA NA 48A SFW}
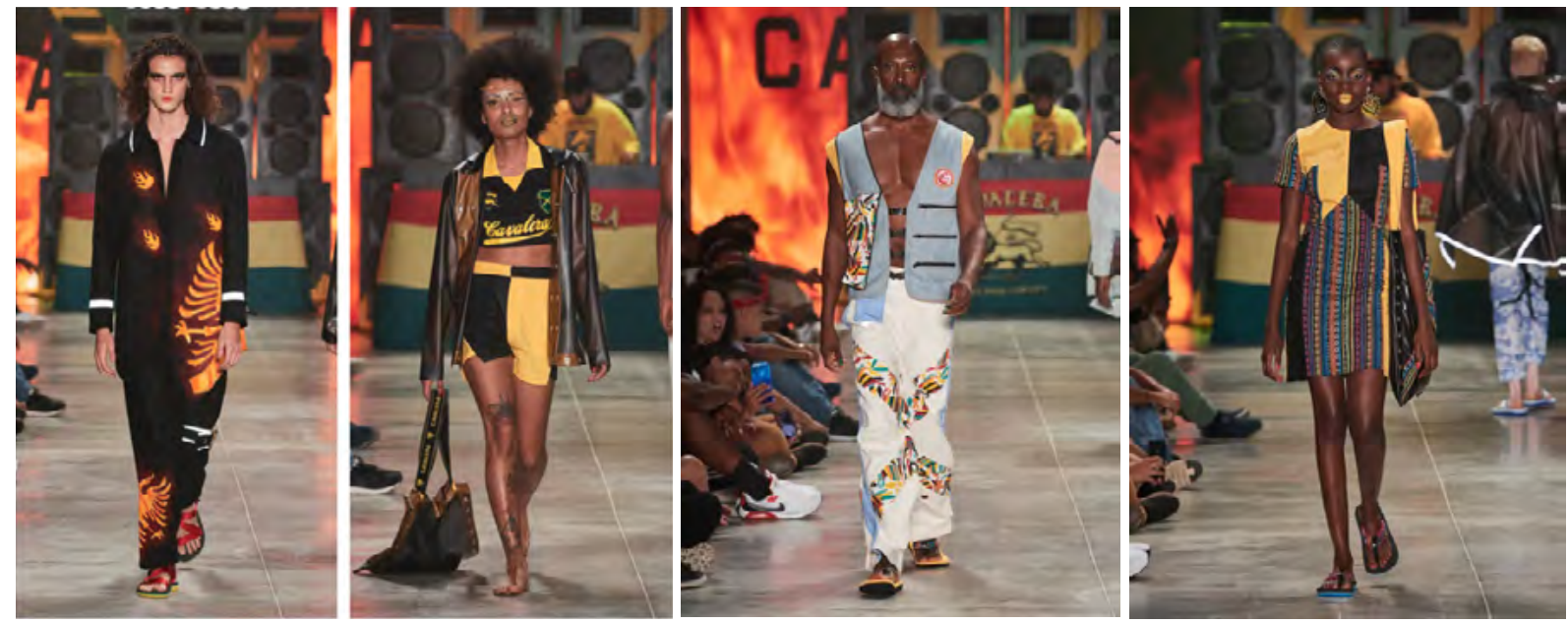

FONTE: Feita a partir de imagens da FFW. Disponível em: https://ffw.uol.com.br/desfiles/sao-paulo/n48/ cavalera/1740450/. Acesso em: 30 mar. 2020.

Pensando no protagonismo negro na moda e também na divulgação da história e da cultura afro-brasileiras, temos o jovem estilista baiano Isaac Silva (figura 3), que teve sua estreia na passarela da São Paulo Fashion Week, na 48 edição do evento, a plataforma de moda de maior visibilidade no Brasil. 


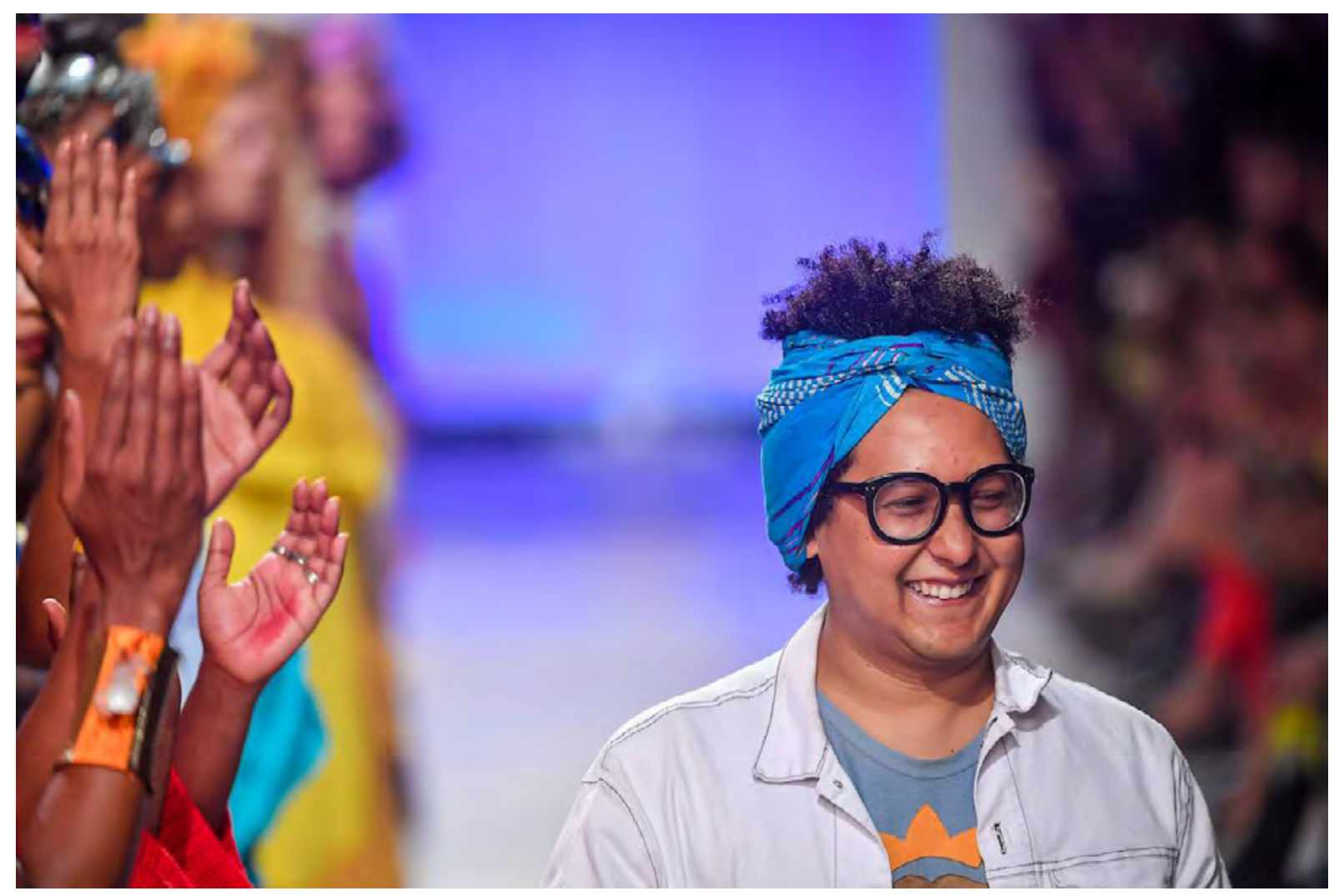

FONTE: Sou de Algodão. Disponível em: https://soudealgodao.com.br/galeria/2018-isaac-silva-44a-casade-criadores/. Acesso em: 12 out. 2020.

Por isso, ele foi o escolhido para ser entrevistado nesta edição da revista a respeito da afromoda. Isaac começou a sua marca há cinco anos, a Isaac Silva Brand, e é adepto da afromoda, usando essa tendência étnica junto com corpos variados na passarela, militando a favor da cultura afro-brasileira. Assim, além de construir uma narrativa mais plural, será possível entender o fenômeno da afromoda enquanto ele acontece e por quem a faz na prática, sendo um ponto de vista único.

Isaac Silva é formado em Design e Gestão, e também com tecnólogo em Produção do Vestuário. Trabalhou com marcas da região do Brás/Bom Retiro, na cidade de São Paulo, e com estilistas como Gustavo Silvestre e Geraldo Couto. No ano de 2016, ele faz seu début na Casa de Criadores, em São Paulo, com o lançamento da coleção Dandaras do Brasil, sobre uma mulher preta ícone, que muitas vezes foi apagada da história brasileira, símbolo de resistência, esposa do Zumbi e pertencente ao Quilombo dos Palmares. 
Os quilombos são um marco histórico-social de resistência, organização político-social e sobrevivência das populações africanas e afro-brasileiras que foram escravizadas no país. Eles eram um local de refúgio, nos quais africanos e afro-brasileiros fugiam da condição que lhes havia sido imposta de escravizados para poder viver em liberdade. E apesar de terem existido inúmeros quilombos, não há tanta divulgação dos mesmos, sendo o mais notório o Quilombo do Palmares, que surge em $1597^{3}$. Dessa forma, na passarela, além de contar um pouco dessa história, o estilista coloca modelos com fenótipos, biótipos e cabeleiras diversas.

Na edição seguinte, a $40^{\mathrm{a}}$ da Casa de Criadores, Isaac Silva apresenta a geração tombamento, remetendo a jovens militantes pretos que visam o combate de qualquer tipo de preconceito e se empoderam por meio da moda e da música, valorizando a identidade negra. 0 movimento teve inspiração na música Tombei, da rapper Karol Conka, que esteve presente no desfile do estilista. A compreensão, por parte da população de afrodescendentes, de que o racismo deve ser combatido e que uma forma de o fazer é por meio da aceitação e da valorização das origens africanas pelos jovens é um passo importante para a mudança do imaginário social inferiorizado que se tem desse grupo étnico.

$\mathrm{Na} 41^{\mathrm{a}}$ edição da Casa de Criadores, a coleção de Isaac mostrou o afrofuturismo da influencer negra Magá Moura, misturando seu estilo pessoal com o dela, usando modelos com diversos fenótipos e biótipos corporais, na mesma linha do casting de seus últimos desfiles. Estava começando a ser delineada a materialização da afromoda, uma tendência de moda étnica ligada à cultura africana e à cultura preta, afro-brasileira, sendo sinônimo de resistência.

Em novembro de 2017, foi a vez de o estilista apresentar a coleção intitulada Seja um raio de sol (figura 4), dedicada à moda afro-brasileira, nome inspirado na filosofia africana do Bantu, com tecidos coloridos e estampas africanas cheias de grafismos, elementos que normalmente não são utilizados nem no dia a dia das pessoas e nem no dia a dia da moda. Na 43a edição da Casa de Criadores, seu desfile teve como tema Xica Manicongo, a primeira travesti não-índia no Brasil. Isaac Silva desenvolveu sua coleção baseado na pesquisa do antropólogo Luiz Mott, deixando sua temática sobre mulheres mais inclusiva a partir do momento que propõe a história de uma mulher negra e trans.

3 GOMES, Flávio dos Santos. Quilombos/Remanescentes de quilombos. In: SCHWARCZ, Lilia M.; GOMES, Flávio (orgs.). Dicionário da escravidão e Ziberdade. São Paulo: Companhia das Letras, 2018. 

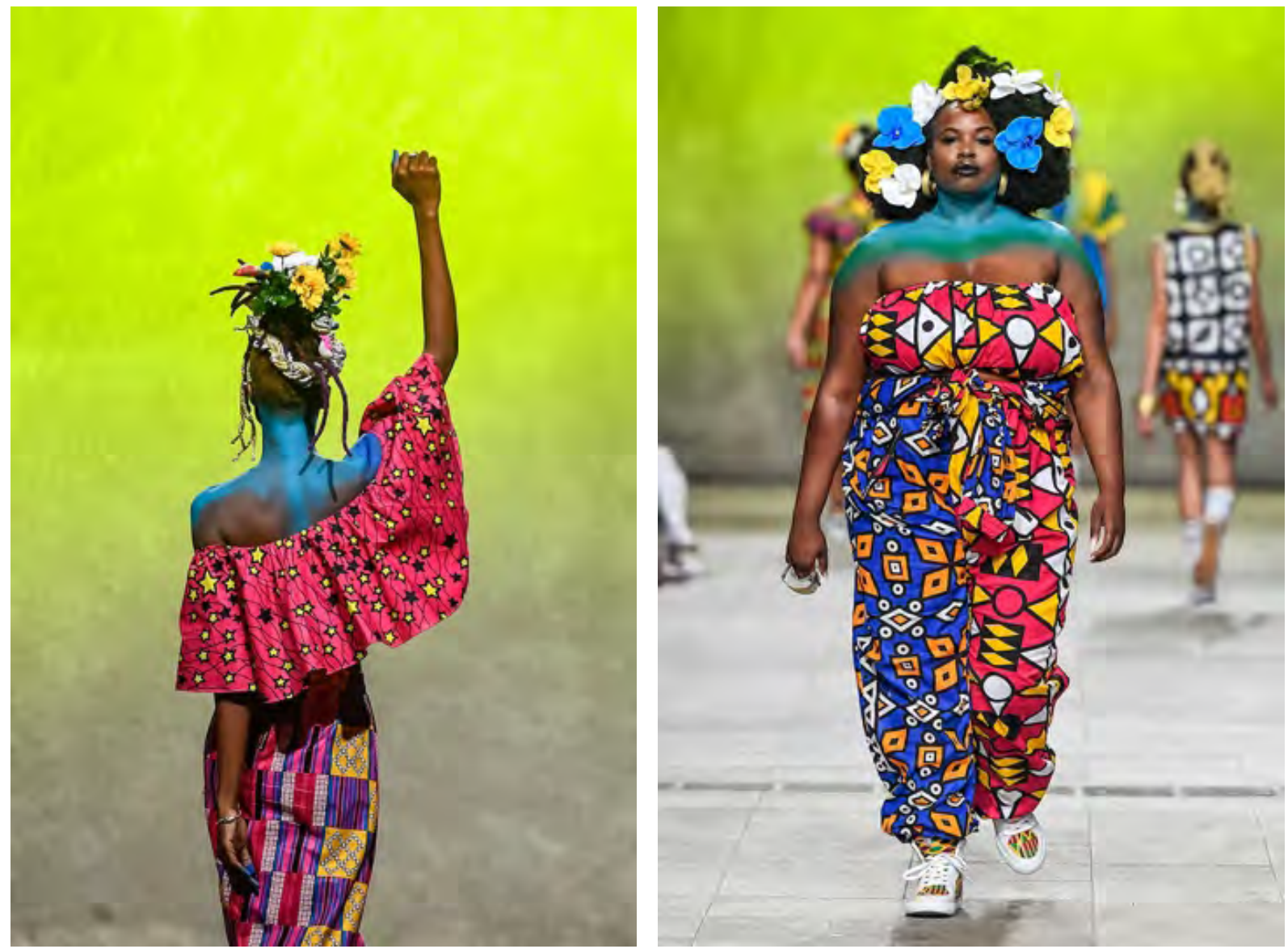

FONTE: Marcelo Soubhia/Agência Fotosite/Divulgação. Disponível em: https://ffw.uol.com.br/desfiles/ sao-paulo/n48/cavalera/1740450/. Acesso em: 30 mar. 2020.

Na 44a edição do evento, o estilista concebe uma coleção homenageando os Orixás (figura 5), entidades pertencentes à religião de matriz africana do candomblé. Para criá-la, Isaac se inspira nas quatro Orixás que fazem o equilíbrio da Terra e da vida: Nãnã Bukuru, que representa as águas paradas; Oyá-Yansã, que tem a simbologia do vento; Oxum, associada à fertilidade; e Yemanjá, retratada pelas águas do mar, seguindo a proposta de ode à cultura afro-brasileira. 0 desfile foi um marco importante porque, apesar de a prática das religiões de matrizes africanas serem permitidas e garantidas na Constituição brasileira, elas sofrem represálias que vão desde um olhar torto até a queima e a destruição dos terreiros.

Durante o processo de colonização do país, a religião imposta a todos que aqui viviam foi o catolicismo, pertencente à matriz judaico-cristã, propiciando a discriminação de tudo o que fosse diferente, inclusive, nas religiões de origem africana, não existe a referência ao diabo, uma vez que elas não acreditam nesse elemento. 

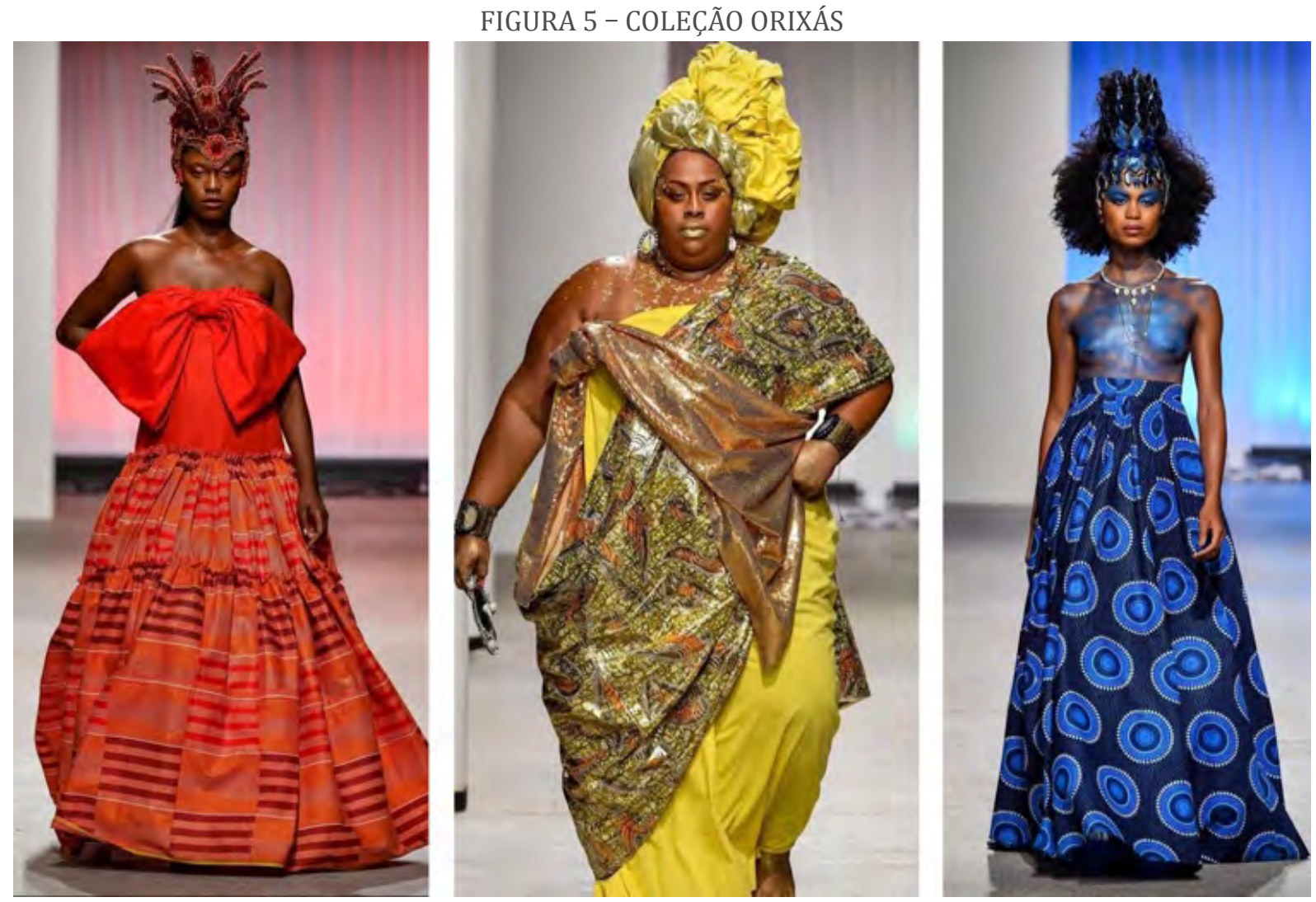

FONTE: Blog Meio que tipo assim4. Disponível em: http://www.meioquetipoassim.com/2018/12/casa-decriadores-44-quarto-dia-de.html. Acesso em: 30 mar. 2020.

Em julho de 2019, na 45a edição da Casa de Criadores, foi o seu último desfile no evento antes do début na São Paulo Fashion Week (SPFW). Essa coleção versou sobre o Egito, para lembrar a todos que o país fica no continente africano e foi o lar de uma das civilizações mais importantes da humanidade: a egípcia. No mês de outubro do mesmo ano, Isaac Silva estreou na $48^{\mathrm{a}}$ edição da SPFW com a coleção Acredite no seu axé (figuras 6 e 7), frase que se tornou marca registrada do estilista. Foi um desfile monocromático, na cor branca, que, usada às sextas-feiras, está ligada à religiosidade afro-brasileira na cidade de Salvador (Bahia), sendo uma forma de resistência preta; já a palavra axé representa as religiões de matrizes africanas, tendo a ver com energia. Seu casting seguiu da mesma maneira de sempre, com a valorização de diversos corpos femininos. Quase que concomitantemente ao desfile, o estilista abriu a sua primeira loja física na região de Higienópolis, na cidade de São Paulo.

\footnotetext{
${ }^{4}$ CASA DE CRIADORES QUARTO DIA. Disponível em: http://www.meioquetipoassim.com/2018/12/casa-de-cria-
} dores-44-quarto-dia-de.html. Acesso em: $30 \mathrm{mar} .2020$. 


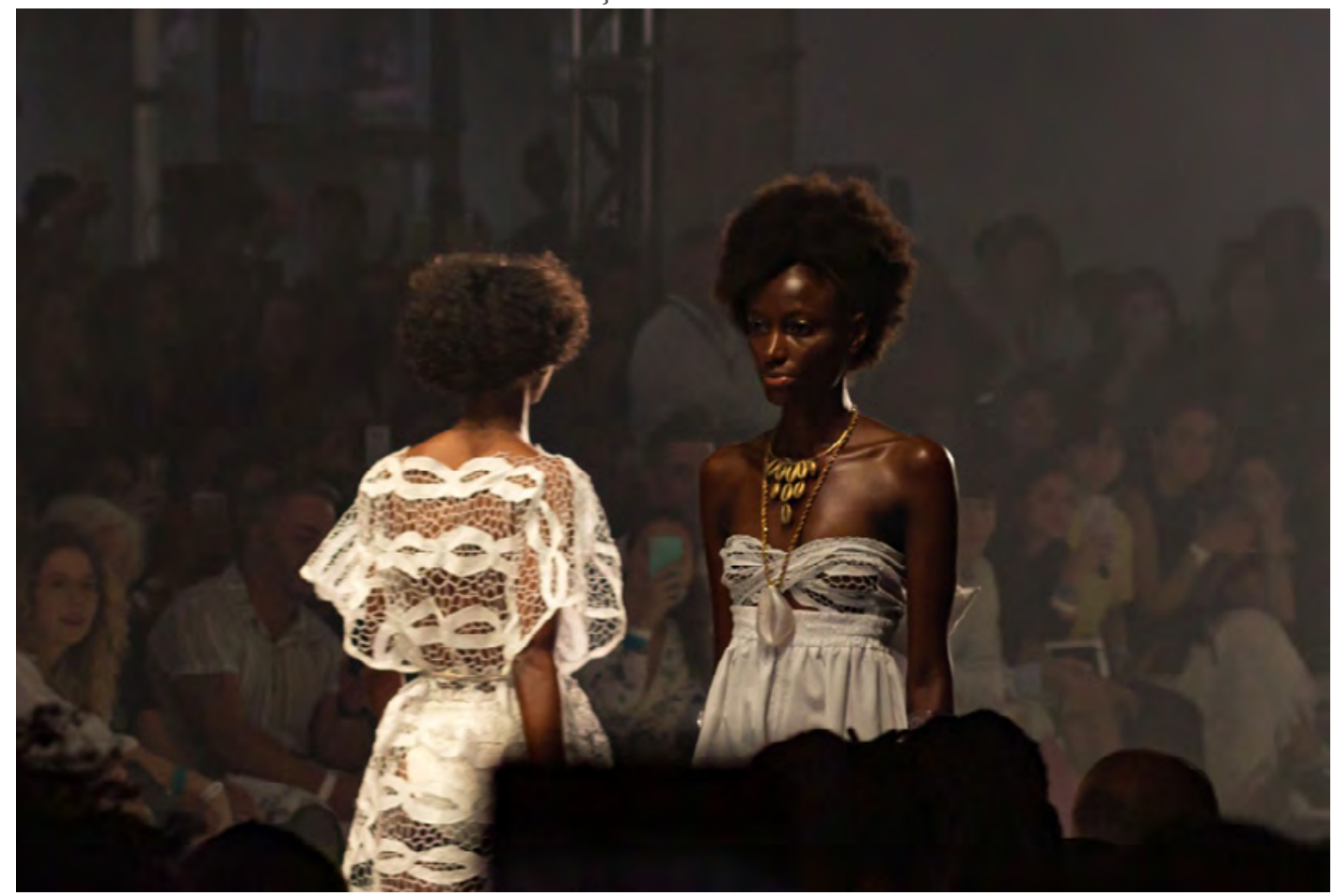

FONTE: Doces Lembranças Fotografia. Material cedido pela empresa.

FIGURA 7 - COLEÇÃO ACREDITE NO SEU AXÉ

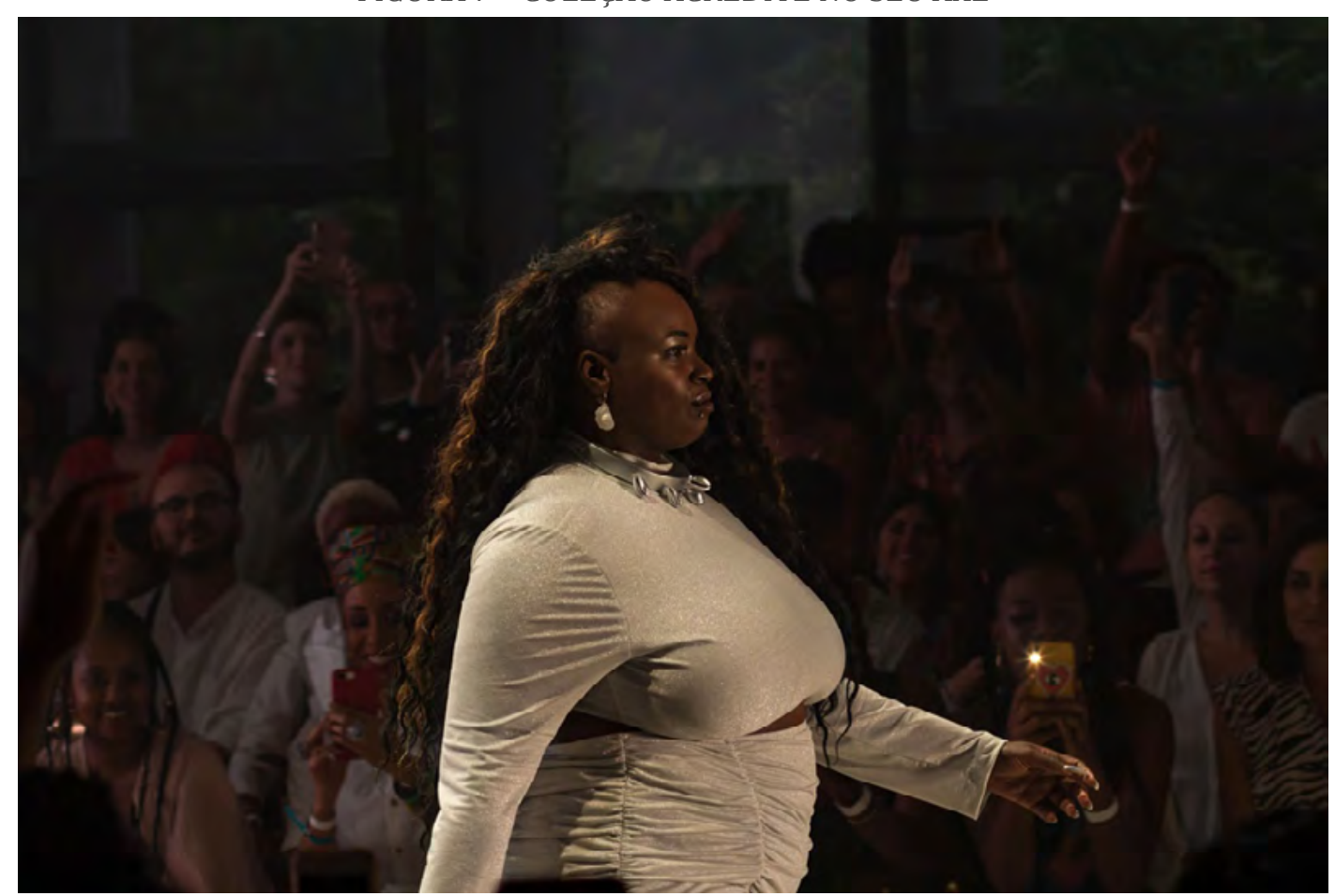

FONTE: Doces Lembranças Fotografia. Material cedido pela empresa. 
A chegada de Isaac Silva à Fashion Week, em 2019, é um marco simbólico da ascensão da afromoda, e, assim, a cultura afro-brasileira está sendo mais valorizada. Entretanto, essa jornada vem de longa data, passando pela Frente Negra Brasileira (FNB), pelo Teatro Negro Brasileiro (TEN), pelo movimento negro, por teóricos e militantes como Clóvis Moura, Abdias Nascimento e Lélia Gonzalez, entre tantos outros grupos, eventos e acontecimentos a partir de 1888. Lembrando também que, desde 2003, vem sendo implementadas leis para proteger, disseminar e valorizar a cultura afro-brasileira.

\section{Isaac, gostaria que contasse um pouco mais sobre você.}

Eu sou o Isaac Silva, estilista e afroempreendedor, tenho 30 anos e nasci na cidade de Barreiras, na Bahia. Há cinco anos, iniciei a minha marca, a Isaac Silva Brand, e, em 2016, foi o meu lançamento na Casa de Criadores. No segundo semestre do ano passado, estreei na São Paulo Fashion Week.

Comecei a gostar de moda na infância, porque eu passava boa parte do tempo em um ateliê de uma amiga da família, a Lorena, que está viva e costura até hoje. Com 13 anos de idade, fui morar em Salvador e lá comecei a ter contato com o universo da moda, acabei fazendo diversos cursos nesse período e decidi pela faculdade na área. Minha mãe sempre me disse que moda era uma profissão de gente rica e que eu deveria ter feito outra coisa, mas hoje em dia ela já me apoia. Posteriormente, decidi que era hora de morar em São Paulo e me mudei para a cidade, onde fiz o curso de tecnólogo em Produção do Vestuário, no Senai, e outras especializações na área para entender qual era o meu lugar na moda.

Vivemos em um mundo que tem o lastro histórico-cultural europeizado e, por isso, todas as áreas, inclusive a da moda, sofrem essa interferência. Dessa forma, desde o padrão estético corporal até as tendências da passarela acabam sendo europeizadas. Na sua estreia na Casa dos Criadores, em abril de 2016, você nos apresentou a coleção Dandara, em que, além de utilizar modelos negras e plus size, abordou Dandara, a companheira de Zumbi, do Quilombo dos Palmares. Por que você decidiu falar sobre esse assunto com uma proposta variada de corpos?

Quando comecei a refletir sobre o que é a moda brasileira e o que é a moda afro-brasileira, vi que o grande mercado desse segmento e os estilistas nunca haviam feito uma pesquisa aprofundada para entender o que é o Brasil e o que é a moda afro-brasileira. Naquele momento, eu precisava falar de um ícone nacional, Dandara, porque o movimento negro, assim como tantas coisas no mundo, é machista, e a mulher negra brasileira tem pouca visibilidade dentro dele. Temos o personagem histórico Zumbi dos Palmares, que a maioria das pessoas conhece, contudo, ele poderia ser ainda mais conhecido e encontrei Dandara e sua história.

Dandara tem um papel dentro do quilombo muito mais significativo do que o do próprio Zumbi porque ela nunca tinha sido escravizada, e Zumbi a conheceu dentro do quilombo. Foi ela quem ensinou Zumbi a liderar, sendo a líder na comunidade. 0 quilombo era uma 
comunidade onde se plantava, criava-se os animais, e Dandara também era uma estrategista militar, ela que comandava os homens à frente. Houve um momento no qual ela e Zumbi precisaram de armas de fogo e Dandara planejou a emboscada contra os portugueses para pegá-las.

O meu papel na moda é contar essa história por meio da roupa. Quis falar sobre as Dandaras do Brasil. Quem são as Dandaras de hoje? Eu imagino que todas as mulheres que estão na resistência até hoje são filhas de Dandara. Se tivessem me contado essa história quando eu era criança ou mesmo no período da faculdade, eu teria outra perspectiva de vida, a minha autoestima teria sido melhor construída.

Por causa disso, na coleção Dandara, quis colocar todo o biótipo nacional que temos, mulheres com a pele mais escura, retintas, com pigmentação, de trança, de black, mulheres plus size. E eu encerrei o desfile com uma iansã interpretada pela negra Sadique, uma artista mulher trans. E foi uma pesquisa muito legal: conhecer mais sobre Dandara nos artigos, perceber que é uma história pouco contada. Assim, uma das minhas prioridades no trabalho é resgatar os ícones históricos que temos e trazer para o meu ambiente, que é a moda.

Como você acha que a moda brasileira reagiu à sua coleção e ao seu casting mais inclusivo, com corpos com diferentes alturas, volumes, tons de pele e cabelos, que se distancia do padrão normatizado da moda brasileira e mundial?

Nos primeiros desfiles, a imprensa de moda não entendeu muito bem a minha proposta, não é à toa que as críticas não foram tão positivas. Mas ela estava tentando compreender, porque nunca tinha visto nada parecido. Quando as críticas saíram, a resposta que dei aos jornalistas foi: "Vocês, para fazer uma crítica ao meu trabalho e ao trabalho de outros estilistas afros, precisam estudar a cultura afro-brasileira. Não é possível fazer nenhum tipo de crítica à moda afro-brasileira se não têm conteúdo, se não sabem o que é uma estampa afro, o que significa o símbolo do búzio, se não sabem o que é o candomblé, uma religião afro-brasileira, não sabem o porquê do uso das tranças e dos turbantes". Acabei instigando a impressa de moda a ter outro olhar sobre a moda afro-brasileira, pois ela tinha uma percepção folclórica, fazendo dessa moda um tipo de artesanato, que não poderia ser chique, que não poderia estar em uma loja, tendo que ser vendida em uma feira ou na rua.

Quando eles compreenderam a moda afro-brasileira, as críticas mudaram, começaram a vê-la a partir de outros ângulos: a contestação social, como um desfile político, que também tem roupa bonita para as pessoas consumirem. Dessa maneira, virei a chave dessa imprensa brasileira que é completamente branca, para ela ter esse outro olhar.

Conforme $\mathrm{li}$ em algumas entrevistas suas na internet, em jornais e revistas (e também eu já sabia), no Brasil o racismo é estrutural. Gostaria de conhecer como as situações que você, um estilista negro e baiano, passou ao construir sua carreira o afetaram e se têm algo a ver direta e indiretamente com a sua militância a favor da mulher preta no mundo da moda, valorizando diferentes aspectos da cultura afro-brasileira, e às vezes até indígena. 
Depois de um tempo vivendo e trabalhando com moda na cidade de São Paulo, percebi que estava em um ambiente totalmente hostil, um lugar preconceituoso, racista, gordofóbico. Eu achava que a moda era contra tudo isso, contra os padrões. E quando vi a moda desse jeito - depois de ter passado pelo cargo de assistente de vários estilistas, ter trabalhado em mercados da moda como na região do Bom Retiro, e com grandes marcas brasileiras -, percebi que eu não teria uma boa colocação, que o esse espaço não tinha me absorvido, e decidi criar a Isaac Silva (há cinco anos). É uma marca que fala sobre o momento que estamos vivendo agora, que quer mostrar para o segmento da moda que podemos usar as ferramentas de estilo, do fashion, pelo amor pela moda, para acabar com o preconceito racial, a misoginia e a gordofobia.

Sobre as culturas afro-brasileira e indígena, eu falo sempre que faço um trabalho afro-indígena. 0 afro está muito mais presente porque eu acredito que, daqui a dez anos, o movimento indígena virá com força total, e agora eu ainda estou fazendo a pesquisa sobre os indígenas, a sua cultura e como trazer isto para a moda. Mas é uma marca afro-indígena porque é a minha ancestralidade, eu também tenho a ancestralidade branca, porém esta já está tão amplamente divulgada que o afro-indígena precisa ser mais mostrado, para que haja respeito por essa cultura.

Sobre preconceito, a todo momento sinto que as pessoas pretas têm que ser três vezes melhores no seu trabalho do que as brancas, e isto sempre me incomodou muito. Eu nunca podia errar e, se errasse, era um caos. Outra coisa recorrente acontecia quando eu chegava às reuniões: ninguém esperava que eu fosse o estilista. Era recebido com outros olhares, porque, quando se fala em estilista, tem-se a construção de uma mulher branca e loira ou a de um homem branco. Por isso, quem não conhecia a marca, em função do meu nome ser Isaac - que é um nome antigo ligado à cultura judaica -, geralmente, achava que eu era judeu, e não negro. Desse modo, o meu fenótipo sempre chocava o outro lado, um entrevistador ou quem participava de uma reunião de trabalho. Sempre tive que lidar com o racismo em todo momento do meu trabalho, até hoje.

Geralmente, quando as modelos negras estão na passarela, elas exibem o cabelo liso, são bem magras e longilíneas, não têm o quadril mais largo, por exemplo, uma característica desse grupo étnico-cultural. Porém, nos últimos anos, isto está mudando. Você acha que o mercado da moda está começando a valorizar a cultura e os povos africanos, bem como os seus descendentes, ou é uma estratégia de marketing?

Não é uma estratégia de marketing, o mundo está mudando e as marcas que não dialogarem com o momento atual irão acabar. Tanto os movimentos de mulheres negras quanto os de brancas falam sobre os padrões de beleza impostos a elas, e, com isso, o mercado da moda deve parar de tentar manter esse biótipo físico como padrão. Acontece a mesma coisa em relação às modelos negras: marcas que só fazem desfiles com modelos brancas estão assumindo que são racistas, e nos dias de hoje nós não toleramos mais marcas racistas, não toleramos mais desfiles racistas. 
Com isso, ao colocarem modelos magras, negras e com o cabelo liso na passarela, teremos outra briga. Queremos mulheres com virilhas, que representam ao menos boa parte dos diferentes corpos. Não é nem que queremos! Atualmente, as mulheres precisam se ver, se elas não se verem, não irão comprar. Uma maneira de boicotar essas marcas é não as consumir, muitas vezes o desfile está maravilhoso, contudo, se eu me vir ali, não irei comprar. Assim, as marcas estão entendendo que é um marketing, que é uma mudança do pensamento social e, por isso, terão que se ajustar.

Você acha que o seu engajamento no mundo da moda, ao lado de outras ações como a do LAB Fantasma, marca comandada pelos irmãos Emicida e Evandro

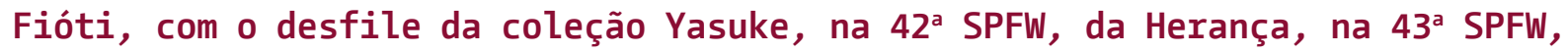
e da Avuá, na $44^{\mathrm{a}}$ SPFW, ou mesmo a última coleção da Cavalera, Skate, punk, Jamaica no país do futebol, apresentada na $48^{\text {a }}$ SPFW, que teve como stylists e diretores artísticos Léo Bronks e Emerson Timba, está fazendo esse segmento de fato prestar atenção e valorizar profissionais negros e a cultura afro-brasileira?

Eu fico feliz porque é um caminho sem volta, cada vez teremos mais profissionais afros e falaremos mais sobre esse tema. E o ponto não é roubar o protagonismo ou o espaço de alguém, dado que existe espaço para todo mundo. Dessa forma, fico muito feliz em saber que existe o LAB Fantasma, os stylists Léo Bronks e Emerson Timba que fizeram o desfile da Cavalera, isto é ótimo! Assim, estamos onde nós deveríamos sempre ter estado, e isto vai crescer mais.

A moda tem como tendência a androgenia, quando se trabalha tipos físicos e roupas que possam atender homens e mulheres. No entanto, isso acontece elegendo corpos longilíneos e enxutos. Assim, quem tem mais busto, costas, barriga, coxas, tem mais peso, é mais baixo, acaba excluído dessa moda. Suas coleções visam atender qualquer consumidor, independentemente de ser homem ou mulher, fitness, consumo saudável, ser mais ou menos abastado ou ter essa ou aquela religião. Por que você decidiu tomar esse rumo?

Porque é um nicho, e a gente tem que entender que o mercado de moda é capitalista, ou seja, existe uma demanda de pessoas que querem comprar roupas. E esse segmento é tão preconceituoso e racista que deixa de ganhar dinheiro por causa disso. Entretanto, a partir do momento que a moda perceber que vai lucrar com uma proposta que fala com todos, todo mundo agirá dessa maneira. Mas as marcas que estão fazendo isto em primeira mão terão um protagonismo maior. Por exemplo, eu já escutei vários relatos de amigas próximas que foram em lojas e ouviram que lá não havia roupas para elas. Por isso, tive que fazer um estudo muito grande sobre modelagem, tecido, preço de produto e atendimento para que todas as pessoas que cheguem à minha loja consigam ter as suas necessidades respondidas: que são o vestir e a roupa. Por causa disso, a minha preocupação sempre foi fazer roupa, essa roupa não tem sexo, não tem gênero, ela é para vestir pessoas. 
0 que você pode comentar sobre afromoda: o uso das roupas e das aparências em corpos políticos?

Eu gosto de pontuar que nós dizemos moda afro-brasileira para fazer uma inclusão social e, assim, minimizar o preconceito racial, porém é tudo moda. Eu faço moda, mas eu sempre enfatizo que crio moda afro-brasileira porque quero vencer a barreira do preconceito racial (racismo). Quando isto acabar, aí poderemos falar só moda. E a moda afro, para mim, é o reflexo do mundo de hoje. No dia de hoje [24 de março de 2020], tivemos o desfile da Dior, e ele foi lindo, com tecidos africanos - eles contrataram dois estilistas negros para trabalhar na coleção, um deles, que fez a parte da alfaiataria, é da África do Sul. Por isso, a moda, atualmente, como nunca tivemos um entendimento do afro, está estudando cada vez mais para não fazer coisas erradas. Então, eu digo que a moda afro-brasileira é o futuro da moda, e, quando ela estiver completamente disseminada e vencer todos os preconceitos, será o momento que poderemos chamá-la apenas de moda.

\section{Agradecimentos}

Agradeço ao meu colega e pesquisador Jonas Nogueira Junior por ter feito a ponte entre mim e o estilista Isaac Silva, e agradeço ao estilista por ter me concedido esta entrevista. 